\title{
The PC index: review of methods
}

\author{
H. McCreadie ${ }^{1}$ and M. Menvielle ${ }^{2}$ \\ ${ }^{1}$ LMU (Ludwig-Maximilians-Universität), Munich, Germany \\ ${ }^{2}$ LATMOS (Laboratoire Atmosphères, Milieux, Observations Spatiales), Paris, France
}

Received: 5 May 2010 - Revised: 11 September 2010 - Accepted: 14 September 2010 - Published: 15 October 2010

\begin{abstract}
The Polar Cap (PC) index is a controversial topic within the IAGA scientific community. Since 1997 discussions of the validity of the index to be endorsed as an official IAGA index have ensued. There is no doubt as to the scientific merit of the index which is not discussed here. What is in doubt is the methodology of the derivation of the index by different groups. The Polar Cap index (PC: PCN, northern; PCS, southern) described in Troshichev et al. (2006) and Stauning et al. (2006), both termed the unified PC index, and the PCN index routinely derived at DMI are inspected using only available published literature. They are found to contain different derivation procedures, thus are not unified. The descriptions of the derivation procedures are found to not be adequate to independently derive the PC indices.
\end{abstract}

Keywords. Ionosphere (Auroral ionosphere)

\section{Introduction}

The polar cap index (PC) is a set of indices (PCN, northern; PCS, southern) determined from measurements of the magnetic field using a single ground station under each polar cap. Constants used in the determination come from an analysis of the magnetic fields in both the solar wind and on the Earth's surface. Only ground based geomagnetic data are required in the calculation once these constants have been determined. Its determination renders it a proxy for the electric field in the solar wind as defined by Kan and Lee (1979).

The original concept of an index which combines magnetic and solar wind data was suggested by Troshichev et al. (1988). It followed from studies by Troshichev et al. (1979, 1985) and a review of polar magnetic disturbances and field

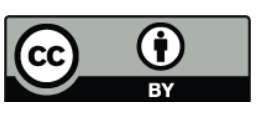

Correspondence to: $\mathrm{H}$. McCreadie (mccreadie@geophysik.unimuenchen.de) aligned currents by Troshichev (1982). The scientific community welcomed the index and Susanne Vennerstrom from the Danish Meterological Institute (DMI) was encouraged to read her PhD on the topic (Vennerstrom, 1991). Her research resulted in the current DMI code that produces the official PCN index (Vennerstrom, 1991; Vennerstrom et al., 1991, 1994; Papitashvili et al., 2001). The next major contribution to the index derivation came from Papitashvili et al. (2001) who, after fixing a programming error in the PCN index showed a recognisable daily variation which is comparable to the seasonal variation and a solar cycle variation within the index. To address the daily and seasonal variation Troshichev et al. (2006) (with the method outlined in Janzhura and Troshichev, 2008) and Stauning et al. (2006) independently derived daily reference levels for each month and obtained new indices.

Unfortunately, because of the nature of the formulation of the PC index in the peer reviewed literature, it is necessary to realize the former PC index methods as they are constantly referred to in the two current index derivations sometimes erroneously (for example Troshichev et al., 2009, describes two major corrections within the papers after being informed about them through the IAGA Sopron 2009 meeting). Table 1 summarizes the derivation procedure of the index through time.

The index has been discussed at every International Association of Geomagnetism and Aeronomy (IAGA) meeting since 1997. It was briefly endorsed until an error was found in a calculation at DMI and a residual daily effect was noted. Thereafter, its derivation has progressed into the form seen in Troshichev, Janzhura and Stauning (2006) and Stauning, Troshichev and Janzhura (2006), both termed the "unified PC index", that are under inspection in this document. The full citation is deliberate here so the reader is aware that the papers are by the same authors.

The index is the culmination of more than 30 years analysis by many people. The main driver of the index formulation

Published by Copernicus Publications on behalf of the European Geosciences Union. 
Table 1. Characteristics of the PC index.

\begin{tabular}{|c|c|c|c|c|c|c|}
\hline Identifier/ year & $\begin{array}{l}\tau \\
\text { (minutes) }\end{array}$ & $\begin{array}{l}\kappa \\
\text { (minutes) }\end{array}$ & data used & Baseline & $\begin{array}{l}\text { Magnetic elements } \\
(\delta M, \delta N)\end{array}$ & $\begin{array}{l}\text { Projection plane } \\
\text { angle }(\gamma) \\
\text { Eq. }(10) \\
\text { (unless stated otherwise) }\end{array}$ \\
\hline AARI\#1_1988 & 1 & 15 & $\begin{array}{l}\text { Vostok } \\
\text { Thule }\end{array}$ & $\begin{array}{l}\text { Deviations from the quiet level } \\
\text { Not defined in literature }\end{array}$ & $\begin{aligned} \delta H_{i} & =H_{i}-H_{b} \\
\delta D_{i} & =D_{i}-D_{b}\end{aligned}$ & $\begin{array}{l}\phi \in\{-90: 5: 90\} \\
\text { best discrete value }\end{array}$ \\
\hline $\begin{array}{l}\text { DMI\#1_1991 } \\
(1975-2001)\end{array}$ & 1 & 15 & Thule & $\begin{array}{l}\text { Baseline }\left(H_{b}, D_{H b}\right) \\
\text { Linear interpolation between } 1 \text { st } \\
\text { January each year, daily values }\end{array}$ & $\begin{array}{l}\delta H_{i}=H_{i}-H_{b} \\
\delta D_{H i}=D_{H i}-D_{H b}\end{array}$ & $\begin{array}{l}\phi \in\{-90: 5: 90\} \\
\text { best discrete value }\end{array}$ \\
\hline $\begin{array}{l}\text { AARI\#2_1991 } \\
(1998-2005)\end{array}$ & 1 & 1 & & same as AARI\#1_1988, chang & in summation interval & \\
\hline $\begin{array}{l}\text { DMI\#2_2001 } \\
\text { (1975-present) }\end{array}$ & 1 & 1,15 & & same as DMI\#1_1991 sofu & are error corrected & \\
\hline DMI\#3_2001 & 1 & 1 & $\begin{array}{l}\text { All polar cap } \\
\text { stations }\end{array}$ & $\begin{array}{l}\text { DMI\#2_2001 (Thule) } \\
\text { AARI\#2_1991 (Vostok) }\end{array}$ & $\begin{array}{l}\delta H_{i}=H_{i}-H_{b} \\
\delta D_{H i}=D_{H i}-D_{H b}\end{array}$ & $\phi$ variable \\
\hline $\begin{array}{l}\text { AARI\#3_2006 } \\
\text { (1978-present) } \\
\text { not } 1996\end{array}$ & 1 & 1,15 & $\begin{array}{l}\text { Vostok } \\
\text { Thule }\end{array}$ & $\begin{array}{l}\text { Baseline }\left(H_{b}, D_{b}\right) \text { not described } \\
\text { Daily quiet level }\left(H_{d}, D_{d}\right) \text { com- } \\
\text { puter derived: filtered mean of } \\
\text { each preceding } 30 \text { day period; } \\
\text { minute vaules calculated daily }\end{array}$ & $\begin{array}{l}\delta H_{i}=H_{i}-H_{b}-H_{d} \\
\delta D_{i}=D_{i}-D_{b}-D_{d}\end{array}$ & $\begin{array}{l}\phi \in\{0: 5: 360\} \\
\text { best discrete value }\end{array}$ \\
\hline
\end{tabular}

(in the peer reviewed literature) was O. A. Troshichev who appears in ALL peer reviewed publications regarding the derivation of both the PCN and PCS indices regardless of the derivation procedure.

In writing this document it became clear that formal criteria for IAGA endorsement of geomagnetic indices were necessary. Mayaud (1980) wrote,
Any geomagnetic index should correspond, as much as possible, to a single and well defined phenomenon and should be derived in such a manner that the data used (given a quantitative parameter, with a given sampling rate, observed at a given station or several stations) be consistent with this phenomenon. Obviously, a series of problems arise. Is it possible to discriminate the phenomenon under consideration from others in the records? Can one 
Table 1. Continued.

\begin{tabular}{llll}
\hline $\begin{array}{l}\text { Normalisation } \\
\text { coefficients }\end{array}$ & $\begin{array}{l}\text { Table of coeffi- } \\
\text { cients (sampling } \\
\text { rate) and (s) }\end{array}$ & $\begin{array}{l}\text { Satellite } \\
\text { Eqs. (16 and 5) }\end{array}$ & $\begin{array}{l}\text { Definition of PC index } \\
F_{k} \text { (Eq. 8) }\end{array}$ \\
\hline None & N/A & \\
& & PC $_{L}=\max \left(A_{Y}\right)$ \\
Eq. $(1) \quad ~$
\end{tabular}

\begin{tabular}{|c|c|c|c|c|}
\hline none & N/A & $\begin{array}{l}\text { N/A } \\
\text { Troshichev } \\
\text { Andrezen } \\
\Delta T=15 \mathrm{~min}\end{array}$ & $\begin{array}{l}\text { MAGPC }=F_{k} F_{k}^{\prime} \\
\text { Eq. (3) }\end{array}$ & \\
\hline $\begin{array}{l}\text { Linear Coefficients } \\
(\alpha, \beta) \text { Eq. }(16)\end{array}$ & $\begin{array}{l}\text { UT hour: season } \\
s=5 \text { or } 15 \mathrm{~min} \\
\text { (unlclear) }\end{array}$ & $\begin{array}{l}\text { IMP-8 1977-1980 } \\
\Delta T=25 \mathrm{~min}\end{array}$ & $P C=\frac{F_{k}}{\alpha}$ & Not available \\
\hline
\end{tabular}

\begin{tabular}{llll}
\hline Orthogonal Coefficients & UT hour; month & IMP-8 1977-1980 & Do not useNot Available \\
- smoothed $\left(\alpha_{\perp}, \beta_{\perp}\right)$ & & $\Delta T=20 \mathrm{~min}$ & $P C=\frac{F_{k}-\beta_{\perp}}{\alpha_{\perp}}$
\end{tabular}

\begin{tabular}{|c|c|c|c|c|}
\hline & & $\begin{array}{l}\ldots \\
\ldots\end{array}$ & & \\
\hline & & $\ldots$ & & official PCN index. \\
\hline \multirow{2}{*}{$\begin{array}{l}\text { Orthogonal Coefficients } \\
- \text { smoothed }\left(\alpha_{\perp}, \beta_{\perp}\right) \\
\text { Eqs. }(5,6)\end{array}$} & UT hour; month & \multirow{2}{*}{$\begin{array}{l}\text { 1966-1977 } \\
\Delta T=\text { various } \\
\text { depends on satellite }\end{array}$} & \multirow[b]{2}{*}{$P C=\frac{\xi\left(F_{k}-\beta_{\perp}\right)}{\alpha_{\perp}}$} & \multirow[t]{2}{*}{ Insightful study } \\
\hline & $\begin{array}{l}\text { As DMI\#2_2001 } \\
\text { Calculated for } \\
\text { each year (3 year } \\
\text { running mean used } \\
\text { from 1965-1998) }\end{array}$ & & & \\
\hline $\begin{array}{l}\text { Orthogonal Coefficients } \\
- \text { smoothed }\left(\alpha_{\perp}, \beta_{\perp}\right) \\
\text { Eqs. }(5,6)\end{array}$ & $\begin{array}{l}\text { UT hour; month } \\
s=15 \text { min interval } \\
\text { (mean from one } \\
\text { minute data with } \\
\text { spikes removed) }\end{array}$ & $\begin{array}{l}\text { IMP-8 1975-1999 } \\
\text { ACE 2000-2003 } \\
\Delta T=20 \mathrm{~min}\end{array}$ & $P C=\frac{\xi\left(F_{k}-\beta_{\perp}\right)}{\alpha_{\perp}}$ & independent derivation \\
\hline $\begin{array}{l}\text { Linear Coefficients - } \\
\text { smoothed }(\alpha, \beta) \\
\text { Eq. (16) }\end{array}$ & $\begin{array}{l}\text { UT hour: season } \\
\text { (unclear) } \\
s=5 \mathrm{~min} \text { interval } \\
\text { (mean from } 1 \mathrm{~min} \\
\text { data) }\end{array}$ & $\begin{array}{l}\text { ACE } 1998-2001 \\
\Delta T=15 \mathrm{~min}\end{array}$ & $\mathrm{PC}=\frac{\xi\left(F_{k}-\beta\right)}{\alpha}$ & official PCS index. \\
\hline
\end{tabular}

identify its zero level? And what is the suitable sampling rate in order to monitor properly its time variation? If the phenomenon varies with longitude and latitude, how does one select the network of stations in order to obtain a reliable result? What are the phenomena which are worth being monitored themselves? Is it justified to answer a need for a characterization of all the disturbances as a whole? In the course of this work we shall see that the answers to these questions are not easy.

A last point is important. In order to solve some of the difficulties encountered, one can be tempted to use standardization processes which are derived from statistical studies based on limited 
samples. We believe that a given index is all the more reliable as it is free of such intermediate inferences.

Mayaud's views are one person's ideas and do not necessarily follow general consensus. As a result of reviewing this index a task force was set up in IAGA Working Group V-dat to review the requirements of endorsing a geomagnetic index. These requirements are outlined in Sect. 4. When reviewing the past indices Mayaud (1980) noted that "it took time to understand that a given index must monitor a single class of geomagnetic variations". Therefore, it is actually no surprise that it has taken time for the PC indices family to evolve.

We open with a short overview of the history of the PC index, followed by a presentation of the current derivation scheme for the unified PC index (Stauning et al., 2006; Troshichev et al., 2006), since these are the most recent attempts to address the question of a unified derivation scheme for both PCN and PCS indices. The actual definition of the index has not changed since 1991 (Troshichev et al., 1991; Vennerstrom et al., 1991). The way in which the elements within it are calculated have changed and these are discussed in Sect. 3. In Sect. 4, we consider the story of the process of the "unified PC index" within the official scientific channels. We present in this section discussions from the IAGA meetings and any other necessary information to tell this story. Finally, we give our comments and recommendations in the perspective of an endorsement of the PC index by IAGA, on the basis of the requirements of endorsing a geomagnetic index that were accepted during the 2009 IAGA Assembly, in Sopron.

We have been careful to follow to IAGA endorsement requirements and we therefore do not consider information that are only available through web pages in accordance with property number 2 of the IAGA endorsement criteria (see Sect. 4) in this review.

\section{The PC index}

\subsection{History}

The first indices which relate to the current Polar Cap index were the $\mathrm{PC}_{L}$ that was developed by Kuznetsov and Troshichev (1977), and the MAGPC, proposed by Troshichev et al. (1979). These indices are not available at present and we do not consider them in detail the present review. However, they are mentioned so the reader gains a full understanding of the history of the index derivation.

The summation of the height of each peak and trough in the horizontal magnetic field measurments for one hour as shown in Eq. (2) is calculated for each polar cap station $(\Sigma$ ). The $\mathrm{PC}_{L}$ index is simply the maximum value (Eq. 1).

$\mathrm{PC}_{L}=\max \left(A_{\Sigma}\right)$ where

$A_{\Sigma}=\left|\sum_{S=0}^{S_{\mathrm{T}}}\left(M_{\text {peak }}\right)_{S+\delta_{p}}-\left(M_{\text {trough }}\right)_{S+\delta_{t}}\right|$

$S_{\mathrm{T}}$ is the total number of peaks and troughs. and

$\delta_{p}=\left\{\begin{array}{l}1 \text { if } S \text { is a peak; } \\ 0 \text { if } S \text { is a trough. }\end{array} \quad \delta_{t}=\left\{\begin{array}{l}1 \text { if } S \text { is a trough; } \\ 0 \text { if } S \text { is a peak. }\end{array}\right.\right.$

The term MAGPC was coined in Troshichev and Andrezen (1985). However, the method of deriving the index was first defined in Troshichev et al. (1979). Here the concept of the horizontal components of the geomagnetic field at a polar cap station oriented in the projection of the 06:00-18:00 LT (local time) was introduced (Eq. 8) with the projection plane angle kept constant $\phi_{i}=0$ in Eq. (10). In Troshichev and Andrezen (1985) the projection plane was changed to 03:0015:00 LT. The MAGPC index is defined in Eq. (3) for the summation interval $\kappa=15 \mathrm{~min}$.

$\mathrm{MAGPC}=F_{k} F_{k}^{\prime}$

where

$F_{k}^{\prime}=\frac{F_{k}}{\kappa}$

$F_{k}$ refers to a quantity the definition of which depends on the used derivation procedure. After this point the correlation between the solar wind magnetic field and the Earth's magnetic field was introduced and the term PC index was coined (Troshichev et al., 1988). The PC index now contained a parameter that was non Earth Based $-\alpha$ defined in Eq. (16). The new PC index was defined as Eq. (4).

$\mathrm{PC}=\frac{F_{k}}{\alpha}$

where $F_{k}$ is defined hereafter in the text, and in Table 1. This was not the only change in the index derivation. The projection plane angle was not allowed to remain constant over a year. The values $\alpha$ and $\phi$ were computed using the solar wind magnetic field measured by the IMP- 8 satellite from the years 1977-1980. The derivation is explained in Sect. 2.3.1.

In 1991 the summation interval $(\kappa)$ was changed from 15 min to 1 min (Troshichev et al., 1991) and a new player was introduced. The PC index was derived by another team (Vennerstrom, 1991; Vennerstrom et al., 1991, 1994; Papitashvili et al., 2001). The most unfortunate occurance was that in the derivation the coefficients were derived using orthogonal coefficients, not linear coefficients. Equation (6) shows the derivation of the orthogonal coefficients (defined in Hald, 1968). The method to derive the coefficients is the same at that outlined in Sect. 2.3.1 for the linear coefficients except Eq. (5) is used instead of Eq. (16). Also the magnetic elements chosen were not the same as the Troshichev team (see Table 1).

$F_{s, \phi}=\alpha_{\perp} E_{m(s)}+\beta_{\perp}$ 
Table 2. Characteristics of the PCN index.

\begin{tabular}{|c|c|c|c|}
\hline & Developed by & Availability & Comments \\
\hline DMI\#1_1991 & $\begin{array}{l}\text { Vennerstrom (1991), } \\
\text { Vennerstrom et al. (1991), } \\
\text { Vennerstrom et al. (1994) }\end{array}$ & $\begin{array}{l}\text { Hard copy WDC-A report } \\
\text { (Vennerstrom, 1994) } \\
\text { which is difficult to get } \\
\text { on short notice. }\end{array}$ & $\begin{array}{l}\text { Coding error: UT signals that should } \\
\text { not be there (see pages } 8-11 \text { of } \\
\text { Papitashvili et al. (2001) } \\
\text { for full details). }\end{array}$ \\
\hline DMI\#2_2001 & $\begin{array}{l}\text { DMI\#1_1991 recalculated } \\
\text { after Papitashvili et al. } \\
\text { (2001) fixed an error in the } \\
\text { original DMI code. }\end{array}$ & $\begin{array}{l}\text { Both } 1 \text { min and } 15 \\
\text { minute resolution from } \\
1975 \text { until present. }\end{array}$ & $\begin{array}{l}\text { Smoothed coefficients } \alpha, \beta \text {, and } \phi \\
\text { are all available for } 12 \text { (months) by } \\
24 \text { (hourly) values (coef } 24 \mathrm{~g} 3 \text {.dat), } \\
\text { but the original } 15 \text { min data sets } \\
\text { used to calculate them are no longer } \\
\text { available. Therefore these original } \\
\text { coefficients are not reproducable. } \\
\text { Baselines defined from quiet winter } \\
\text { levels for all geomagnetic field } \\
\text { components at THL (qwdthl.dat). }\end{array}$ \\
\hline DMI\#3_2001 & $\begin{array}{l}\text { Papitashvili et al. (2001) } \\
\text { using the Vennerstrom } \\
\text { corrected method (Please } \\
\text { refer to the paper for } \\
\text { details) }\end{array}$ & $\begin{array}{l}\text { coefficients available on } \\
\text { request to the authors }\end{array}$ & $\begin{array}{l}\text { The index is used only by } \\
\text { Papitashvili et al. (2001) for the } \\
\text { study of potential solar cycle effects } \\
\text { on PCN but is included here because } \\
\text { it highlights the difficulty } \\
\text { in reproducing the index }\end{array}$ \\
\hline DMI\#4_2006 & $\begin{array}{l}\text { Stauning et al. (2006) } \\
\text { Independent development }\end{array}$ & $\begin{array}{l}\text { All parameters including } \\
\text { computer code are } \\
\text { available on request } \\
\text { to the authors. }\end{array}$ & \\
\hline
\end{tabular}

$\alpha_{\perp}=\frac{S_{y}-S_{x} \pm\left(\left(S_{y}-S_{x}\right)^{2}+4 S_{x y}^{2}\right)^{1 / 2}}{2 S_{x y}}$, and

$\beta_{\perp}=\overline{E_{m}}-\alpha_{\perp} \bullet \overline{F_{s, \phi}}$

where

$S_{x}=\frac{1}{N-1} \sum_{s}\left(F_{s, \phi}-\overline{F_{s, \phi}}\right)^{2} ;$

$S_{y}=\frac{1}{N-1} \sum_{i}\left(E_{m(s)}-\overline{E_{m}}\right)^{2}$

$S_{x y}=\frac{1}{N-1} \sum_{s}\left(F_{s, \phi}-\overline{F_{s, \phi}}\right)\left(E_{m i}-\overline{E_{m}}\right)$

What was hoped to be a family of indices, where the team at DMI were deriving the PCN index and the team at AARI derived the PCS index, with similar algorithms, never happened.

Papitashvili et al. (2001) introduced a scale coefficient ( $\xi=1 \mathrm{~m} \mathrm{mV}^{-1}$ ) to make the units of the index compatible with the merging electric field. This was included by Troshichev et al. (2006) and Stauning et al. (2006) versions of the PC index.
The next major initiative involved an interpolation of the baselines and a change in the horizontal magnetic components used (Stauning et al., 2006). However, at the same time Troshichev et al. (2006) changed the way the daily quiet level was calculated.

At present we have three indices available. Two are called the unified polar cap indices (Troshichev et al., 2006; Stauning et al., 2006) and PC index derived from the team at DMI.

The derivation of each index is summarized in Table 1. The nomenclature used in this document that refers to different methods used to develop the polar cap (PC) index is used in the first column of Table 1 and described in Table 2 and Table 3. The labels were originally suggested by Stauning (personal communication DMI 15 July 2009/PSt). In order to keep the time line which is useful in some dialogues we also include the year the first publication regarding that method was published in the labels.

\subsubsection{The northern Polar Cap index: PCN}

Indices labelled PCN refer to an index created using the geomagnetic polar cap station Qaanaaq (formerly known as Thule) in Greenland ( $85.4^{\circ}$ corrected geomagnetic latitude, invariant latitude $86.5^{\circ}$, magnetic local noon $\left.\sim 14 \mathrm{UT}\right)$. Its 
Table 3. Characteristics of the PCS index.

\begin{tabular}{|c|c|c|c|}
\hline & Developed by & Availability & Comments \\
\hline AARI\#1_1988 & Troshichev et al. (1988) & Not available & \\
\hline AARI\#2_1991 & Troshichev et al. (1991) & Not available & $\begin{array}{l}\text { Lukianova papers } \\
\text { sometimes use the AARI\#2 } \\
\text { method but not the indices } \\
\text { that were available to the } \\
\text { public. The derivation } \\
\text { process was not stated in } \\
\text { any of the papers. }\end{array}$ \\
\hline AARI\#3_2006 & $\begin{array}{l}\text { Troshichev et al. (2006), } \\
\text { Janzhura and Troshichev (2008), } \\
\text { Troshichev et al. (2009) }\end{array}$ & $\begin{array}{l}\text { Both } 1 \text { min and } 15 \\
\text { minute values (personal } \\
\text { communication with } \\
\text { Oleg Troshichev. }\end{array}$ & $\begin{array}{l}\text { No coefficients are } \\
\text { available but will be made } \\
\text { available in the future. }\end{array}$ \\
\hline
\end{tabular}

IAGA code is THL. The indices are formally calculated at the Danish Meteorological Institute (DMI).

The characteristics of the PCN indices derived using the different methods are summarized in Table 2 . The PCN index is available from http://web.dmi.dk/projects/wdec1/pen/pcn. html.

\subsubsection{The southern Polar Cap index: PCS}

Indices labelled PCS refer to an index created using the geomagnetic polar cap station Vostok, in Antarctica ( $-83.4^{\circ}$ corrected geomagnetic latitude, invariant latitude $-83.3^{\circ}$, magnetic local noon $\sim 13 \mathrm{UT}$ ). Its IAGA code is VOS. The index is formally computed at the Arctic Antarctic Research Institute (AARI).

The PCS index is available on request from http://www. aari.nw.ru/clgmi/geophys/pc_main.htm. The characteristics of the PCS indices derived using the different methods are summarized in Table 3.

\subsection{Derivation of the unified PC index}

The current PC index is first defined. Thereafter, each subsection of this chapter is devoted to outlining in detail each element which requires further explanation. A complete summary of elements used in each derivation of the index is given in Table 1 and a brief outline is given in Sect. 2.1.

\subsubsection{Definition of the current PC index}

The current PC index is defined as

$\mathrm{PC}=\frac{\xi\left(F_{k}-\beta_{k}\right)}{\alpha_{k}}$.

where $F_{k}$ is the magnetic disturbance vector. $F_{k}$ is simply the projection of the actual magnetic disturbance vector $(\delta M, \delta N)$ perpendicular to the direction of the DP2 transpo- lar current flow. It was first defined, although not clearly, in Troshichev et al. (1979) (see Sect. 2.3 for details):

$$
F_{k}=\sum_{i=(1-k) d}^{(j-k) d} \delta M_{i} \sin \gamma_{i} \mp N_{i} \cos \gamma_{i}
$$

$$
\{j=1, \ldots, d\}\left\{k=1, \ldots k_{T}\right\} \text { and } d=\frac{\kappa}{\tau}
$$

$\tau$ denotes the sampling rate (minutes), subscript $i$ denotes the sample identifier $\left(i=1, \ldots, \tau_{T}\right)$ where the total number of samples in a given summation interval is $\tau_{T}, \kappa$ summation interval (minutes), $\kappa_{\mathrm{T}}$ denotes total number of summations in one day, and $\xi$ is a scaling value of $1 \mathrm{~m} \mathrm{mV}^{-1}$.

The disturbance vector is described by the horizontal magnetic measurements made in the geographic coordinate system:

$$
\delta M_{i}=M_{i}-M_{b}-M_{d}
$$$$
\delta N_{i}=N_{i}-N_{b}-N_{d}
$$

where $(M, N)$ denote magnetic element pairs $(H, D),(X, Y)$ or $\left(H, D_{H}\right)$ (defined in Fig. 5). The subscript $b$ denotes baseline values - secular variation, and the subscript $d$ denotes daily regular variations.

The rotation angle $\gamma$ is defined as:

$$
\begin{array}{cc}
\gamma_{i}=\lambda+(\mathrm{UT})_{i} 15^{\circ} \mp D_{E}+\phi_{i} & \text { for }\{M, N\}==\{H, D\} \\
& \text { or }\left\{H, D_{H}\right\} \\
\gamma_{i}=\lambda+(\mathrm{UT})_{i} 15^{\circ}+\phi_{i} & \text { for }\{M, N\}==\{X, Y\}
\end{array}
$$

where $\lambda$ denotes geographic longitude; $D_{E}$ mean magnetic declination (degrees); UT universal time; $\phi$ UT-dependent angle between DP2 transpolar current and the noon-midnight local time meridian; $\alpha$ and $\beta$ are normalisation coefficients (Eq. 16). When declination is positive Eastwards Eqs. (8) and (10) use a "+" for the Southern Hemisphere and a "-" for the Northern Hemisphere (Troshichev et al., 1988).

The normalisation coefficients $\alpha$ and $\beta$, and the angle $\phi$ are defined in a table for each UT hour and calendar month. To obtain the values for times between defined elements a linear relation is assumed. 


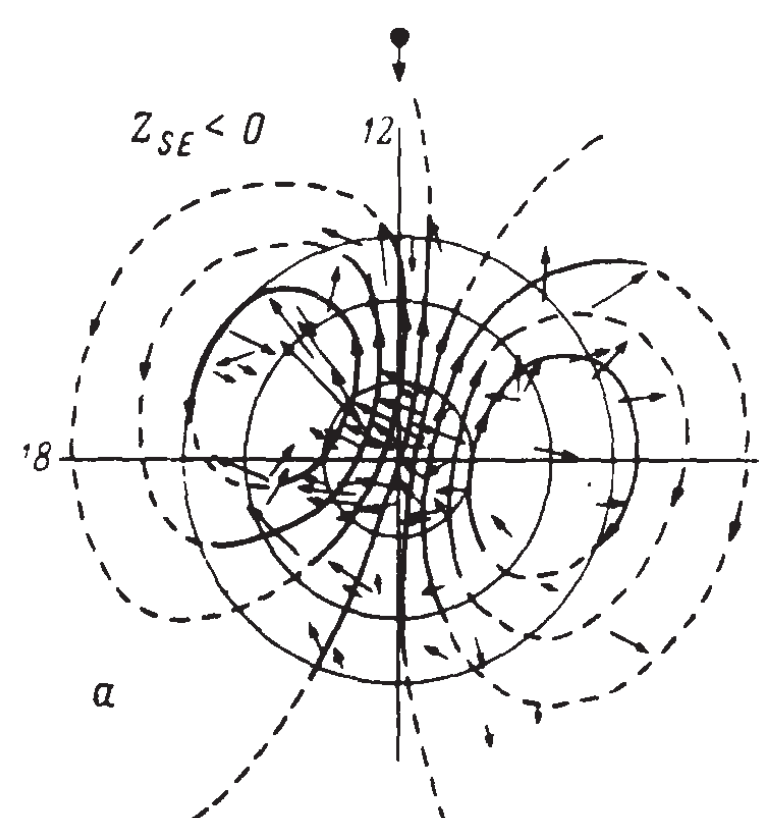

Fig. 1. From Kuznetsov and Troshichev (1975 and 1977). Distribution of disturbance vectors in the polar cap and the equivalent current system DP2 $\left(Z_{\mathrm{SE}}<0\right)$. Time shown is in local time. The grey circles represent latitude.

\subsection{Description of projection plane angle}

The projection plane angle is simply the rotation of the geographic coordinate system into the local time (LT) coordinate system, which is invariant with respect to the DP2 current system.

A simplified DP2 current system is shown in Fig. 1 for the Z-component of the interplanetary magnetic field southward $\left(B_{\mathrm{z}}<0\right)$ and various $B_{\mathrm{y}}$-components. The magnetic disturbance vectors are shown and their equivalent current system is depicted by black lines. Over the polar cap the magnetic disturbance is almost in the 06:00-18:00 LT meridian. The grey circles denote geographic latitude.

The Earth rotates under the DP2 current system therefore the geographic coordinate system is rotating with respect to the DP2 current system. Figure 2 shows the geographic coordinate system rotating under the Local Time (LT) system for an arbitrary latitude (circle). The X-Y coordinates are the geographic North and East axes, respectively. In this diagram the angle $\gamma$ simply refers to local time $\gamma=\lambda+$ (UT) $\not \subset 15^{\circ}$, where UT is universal time and $\lambda$ is longitude. If the latitude chosen is under the polar cap and it is assumed that the DP2 current system is homogenous under the polar cap then the magnetic field disturbance caused by the DP2 current system would show the exact same measurements at each UT. This does not happen in geographic coordinates as the coordinates rotate. Figure 3 depicts the rotating coordinate system shown in Fig. 2 with a disturbance vector $\boldsymbol{R}$ constant for

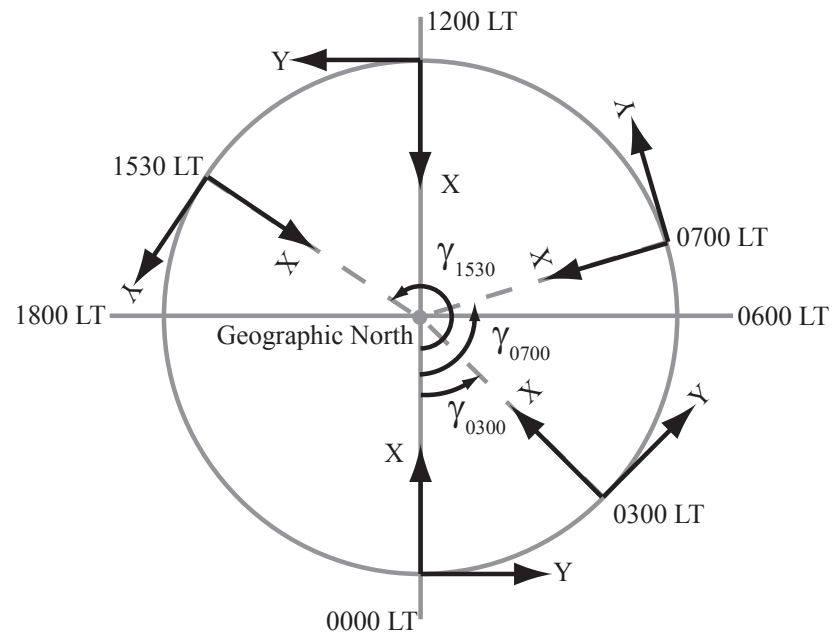

Fig. 2. Rotating geographic coordinate system.

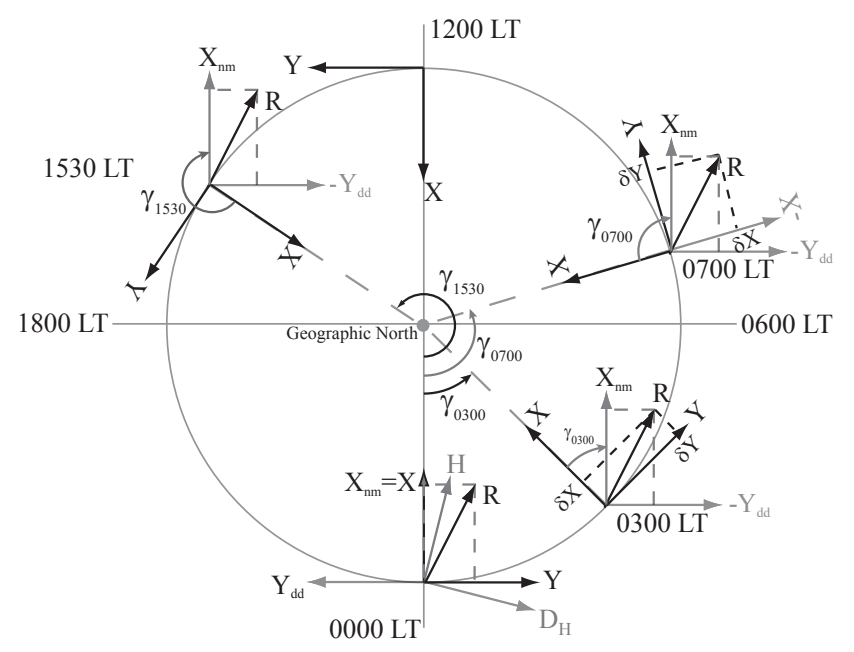

Fig. 3. Rotation of the geographic coordinate system with respect to invariant local time for a constant disturbance vector $\boldsymbol{R}$.

one UT. The LT invariant coordinate system is depicted by ( $\left.X_{\mathrm{nm}}, Y_{\mathrm{dd}}\right)$, where the $X_{\mathrm{nm}}$ is in the noon-midnight meridian and $Y_{\mathrm{dd}}$ is in the dawn dusk meridian. A clockwise axes rotation is required to orient the $\mathrm{X}-\mathrm{Y}$ axes in the midnightnoon meridian and a flip of $180^{\circ}$ to rotate the Y-axis in the dawn-dusk meridian.

The graphical description for a clockwise rotation of an arbitrary right hand 2-dimensional coordinate system is shown in Fig. 4 where

$$
\begin{aligned}
& r_{i}=r_{i i} \cos \phi-r_{j j} \sin \phi \\
& r_{j}=r_{i i} \sin \phi-r_{j j} \cos \phi \\
& \left(\begin{array}{l}
r_{i} \\
r_{j}
\end{array}\right)=\left(\begin{array}{cc}
\cos \phi & -\sin \phi \\
\sin \phi & \cos \phi
\end{array}\right)\left(\begin{array}{l}
r_{i i} \\
r_{j j}
\end{array}\right)
\end{aligned}
$$




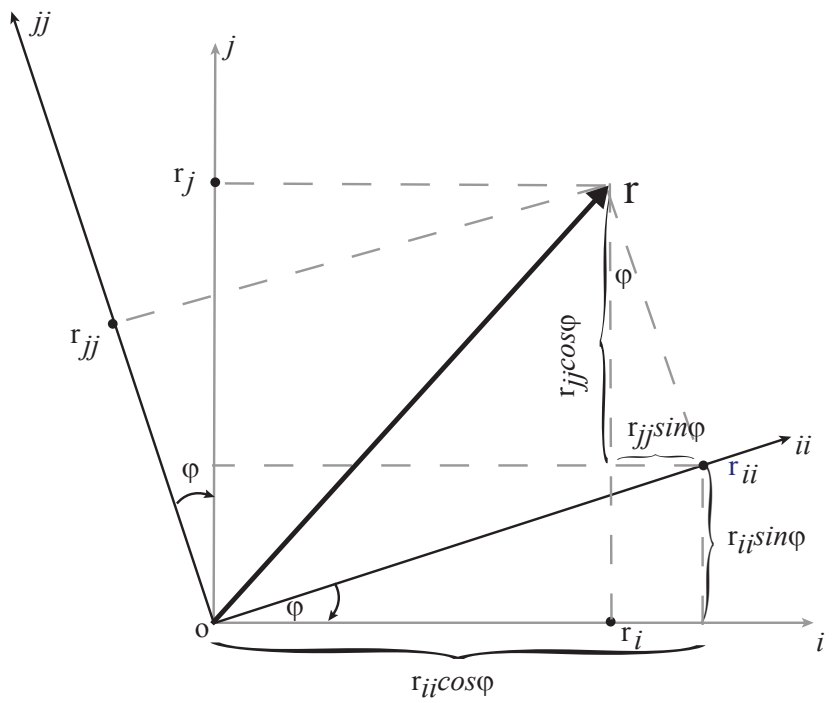

Fig. 4. Clockwise rotation of an arbitrary right hand 2-dimensional coordinate system.

In the case of the LT coordinate system shown in Fig. 3, the $\mathrm{i}$-axis is flipped. Therefore the coordinate transform matrix is given by

$$
\begin{aligned}
& \left(\begin{array}{c}
-r_{i} \\
r_{j}
\end{array}\right)=\left(\begin{array}{cc}
\cos \phi & -\sin \phi \\
\sin \phi & \cos \phi
\end{array}\right)\left(\begin{array}{l}
r_{i i} \\
r_{j j}
\end{array}\right) \\
& \Rightarrow\left(\begin{array}{c}
r_{i} \\
r_{j}
\end{array}\right)=\left(\begin{array}{cc}
-\cos \phi & \sin \phi \\
\sin \phi & \cos \phi
\end{array}\right)\left(\begin{array}{c}
r_{i i} \\
r_{j j}
\end{array}\right)
\end{aligned}
$$

For the case of the magnetic field vectors oriented in the geographic system (X, Y) shown in Fig. 3 the projection of the disturbance vector $\boldsymbol{R}(\delta Y, \delta X)$ onto the dawn-dusk meridian (06:00 LT-18:00 LT) is given by $F_{\mathrm{dd}}$ and the projection of the disturbance vector $\mathrm{R}(\delta Y, \delta X)$ onto the midnight-noon meridian (00:00 LT-12:00 LT) is given by $F_{\mathrm{mn}}$

$$
\begin{gathered}
F_{\mathrm{dd}}=\delta X \sin \gamma-\delta Y \cos \gamma \\
F_{\mathrm{mn}}=\delta X \cos \gamma+\delta Y \sin \gamma \\
\gamma=\lambda+(\mathrm{UT}) 15
\end{gathered}
$$

where the projection plane angle $\gamma$ is just the local time and of course $\lambda$ is the longitude. This was defined in Troshichev et al. (1979).

If the current causing the disturbance vector $\boldsymbol{R}$ is not exactly oriented in the noon-midnight meridian then the axes should be further rotated to depict this. The projection plane angle is then given by

$\gamma=\lambda+(\mathrm{UT}) 15+\phi$

This is used in DMI\#4_2006, Stauning et al. (2006).

Also shown on Fig. 3 are the axes for the magnetic elements $\left(H, D_{H}\right)$ at 00:00 LT. It is clear from this that the vectors must first be rotated into the $(\mathrm{X}, \mathrm{Y})$ plane. Therefore, when the magnetic elements $\left(H, D_{H}\right)$ and $(H, D)$ are used the projection plane angle must also include this rotation by using the average declination measured in degrees $\left(D_{E}\right)$. Thus:

$F_{\mathrm{dd}}=\delta H \sin \gamma-\delta D \cos \gamma$

$\gamma=\lambda+(\mathrm{UT}) 15-D_{E}+\phi$

The value of $D_{E}$ does not change with time in the calculations so magnetic secular variation is not considered. Please note that when in the Southern Hemisphere the minus signs in Eqs. (13) and (15) become positive. This was first defined in Troshichev et al. (1988).

For all of the PCS indices $D_{E}$ was defined in Troshichev (1988); Vostok: $D_{E}=-117^{\circ}$, Thule: $D_{E}=285^{\circ}$.

$D_{E}$ is not defined in the literature for DMI\#1_1991, DMI\#2_2001, and DMI\#3_2001 but can be found in the observatory data-base either at Intermagnet or the World Data Centers.

$D_{E}$ is not required for DMI\#4_2006.

Please note: with the above method it does not matter if $\left(H, D_{H}\right)$ or $(\mathrm{X}, \mathrm{Y})$ are used to define $\mathrm{F}$ if the mean declination over time does not significantly change, therefore the AARI method and the DMI methods are comparable. Figure 5 shows the orientation of geomagnetic vectors with repect to geographic coordinates. It is clear that the declination is $D=H \sin \left(D_{E}\right) ; D_{H}$ is the horizontal component in the easterly direction perpendicular to $\mathbf{H}$ in nanoteslas and is $D_{H}=H \tan \left(D_{E}\right)$; If $D_{E}$ is very small then $D_{H} \cong H \sin \left(D_{E}\right)$. Hence $D_{H} \cong D$ (used in DMI\#1_1991, DMI\#2_2001).

Also note there is confusion surrounding the exact coordinate axes presented here and that noted in Troshichev et al. (1979):

...the projection of the disturbance vector on the axis 06:00-18:00 LT corresponds to disturbances generated by the north-south $\left(B_{\mathrm{Z}}\right)$ component of the IMF, while the projection on the axis 12:00-24:00 LT corresponds to disturbances due to azimuthal $\left(B_{\mathrm{y}}\right)$ component, that is,

$$
\begin{aligned}
F_{i}\left(B_{\mathrm{z}}\right) & =\delta X_{i} \sin \alpha_{i}-\delta Y_{i} \cos \alpha_{i} \\
F_{i}\left(B_{\mathrm{y}}\right) & =\delta X_{i} \cos \alpha_{i}-\delta Y_{i} \sin \alpha_{i} \\
\alpha_{i} & =\lambda+(\mathrm{UT})_{i} \times 15^{\circ}
\end{aligned}
$$

where $\lambda$ is the geographical longitude. According to Eq. (1), the value $F_{i}\left(B_{\mathrm{Z}}\right)$ is positive when $B_{\mathrm{Z}}<$ 0 (disturbance vector directed from dawn to dusk) and is negative when $B_{\mathrm{Z}}<0$ (direction to dawn); the value $F_{i}\left(B_{\mathrm{y}}\right)$ is positive when $B_{\mathrm{y}}>0$ (direction to noon) and is negative when $B_{\mathrm{y}}<0$ (direction to midnight).

It is clear from the second paragraph that the invariant local time axes are defined as positive towards 1800 and positive towards 1200 as depicted here in Fig. 3.

Also, please note: In the first paragraph page 218 Troshichev et al. (1979) is an error defining the reference 


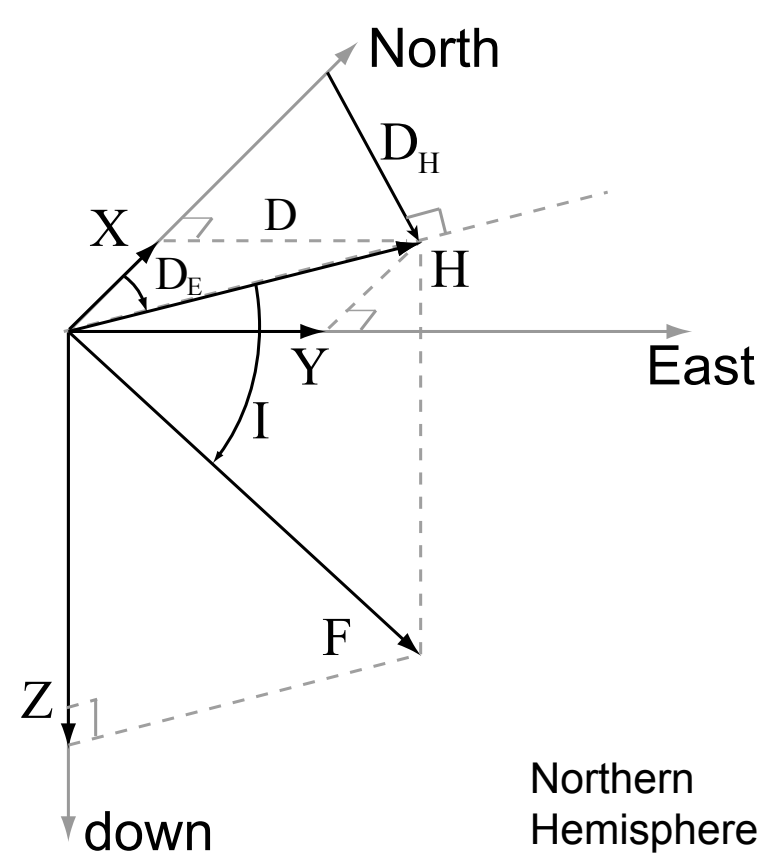

Fig. 5. Definition of magnetic elements. $\mathbf{F}$ is the total magnetic field vector; $\mathbf{I}$ is the inclination in degrees; $D_{E}$ is the declination in degrees; $\mathbf{D}$ is the declination in nanoteslas; $D_{H}$ is the horizontal component in the easterly direction perpendicular to $\mathbf{H}$ in nanoteslas; $H$ is the horizontal component along the magnetic meridian in a northerly direction in nanoteslas. $\mathrm{X}, \mathrm{Y}$, and $\mathrm{Z}$ are the magnetic components in the geographic coordinate system (WGS84) in nanoteslas. All vectors are shown in their respective positive directions.

Kuznetsov and Troshichev (1976) (sic) should be Kuznetsov and Troshichev (1977).

\subsubsection{Derivation of the normalisation coefficients $\alpha$ and $\beta$, and the angle $\phi$}

The normalisation coefficients $\alpha$ and $\beta$ and $\phi$ are derived by the linear relation

$$
F_{s, \phi}=\alpha E_{m(s)}+\beta \quad \phi \in\{-90: x: 90\}
$$

where $E_{m}$ is the merging interplanetary electric field (sometimes called the geoeffective electric field). $E_{m}$ was defined by Kan and Lee (1979):

$$
\begin{gathered}
E_{m(s)}=V_{\mathrm{SW}}\left(B_{\mathrm{z}}^{2}+B_{\mathrm{y}}^{2}\right)^{1 / 2} \sin ^{2}\left(\frac{\theta}{2}\right)=V_{\mathrm{SW}} B_{\mathrm{T}} \sin ^{2}\left(\frac{\theta}{2}\right) \\
\text { where } \theta=\cos ^{-1}\left(\frac{B_{\mathrm{z}}}{B_{\mathrm{T}}}\right)
\end{gathered}
$$

Here $V_{\mathrm{SW}}$ is the magnitude of the solar wind velocity, $B_{\mathrm{y}}$ and $B_{\mathrm{Z}}$ are the IMF azimuthal and vertical components, respectively, and $\theta$ is the IMF clock-angle i.e. the angle between the IMF transverse component $\left(B_{\mathrm{T}}\right)$ and the geomagnetic dipole at the subsolar point on the magnetopause $\left(B_{\mathrm{Z}}\right)$. All values of the solar wind velocity and magnetic field strengths are obtained from satellites. Satellite time is shifted to $12 R_{\mathrm{E}}$ (Earth Radii GSM, sub-solar point) using the solar wind velocity. Then a time delay of $\Delta T$ is required for the electric field to travel from this point to the ground.

For each calendar month, over the span of satellite data which defines the merging electric field, the disturbance vector $F_{k}$ (Eq. 8) is calculated for all angles $\phi$. For each hour the linear regression coefficients $(\alpha, \beta)$ between the disturbance vectors and the merging electric field are found. The angle $\phi$ for which the correlation coefficient between the merging electric field and $F_{k}$ is maximum, is chosen and those coefficients retained for that hour and month. Finally, the time series of the coefficients are smoothed to obtain the final tables of coefficients to be used for the PC derivation. These coefficients never change.

Troshichev, Janzhura and Stauning (AARI\#3_2006) are extremely unclear about this procedure (see Sect. 3.1).

Stauning, Troshichev and Janzhura (DMI\#4_2006) derived the coefficients over a span of 29 years using IMP-8 satellite data (1975-1999) ACE data (2000-2003). From one minute samples the maximum and minimum values are removed for each $15 \mathrm{~min}$ interval and the mean calculated. These 15-min samples are the basis for deriving the normalisation coefficients.

Their method is: The data interval is divided into 5 year sequences with a step every two years (the authors are not clear whether the 5 years is constantly five years or contains unused portions). The data are then divided into months. For each UT hour in a month the average electric field is calculated (Ema). Then the magnetic disturbance vector is calculated for every angle $\phi=\{0: 10: 360\}$. The average of the projected disturbance vectors $(\mathrm{Fva})$ is then used in determining the best angle for that time using (reader please note, Eq. 18 is not the linear correlation coefficient, see Aitken, 1947)

$R=\frac{\sum\left(\left(F_{k}-\mathrm{Fva}\right)\right)\left(E_{m}-\mathrm{Ema}\right)}{\sqrt{\sum\left(f_{k}-\mathrm{Fva}\right)^{2} \sum\left(E_{m}-\mathrm{Ema}\right)^{2}}}$

where the summation is extended over all available 15-min samples through the data interval. When the largest $R$ is found a least squares fit is used to form a parabola using the previous and following two values. Again it is unclear but it is assumed the maximum of the parabola will give the precise value of the angle $\phi$ for the given month and UT hour. This means $\phi$ can be any numeric value, not just the integers used to determine the parabolic function. These monthly values are then averaged for the five year epoch. These values are then exposed to Gaussian smoothing over month and UT hour using the weight function:

$\mathrm{WG}=\exp -(H-H 0)^{2} / \mathrm{XHR}^{2}-(M-M 0)^{2} / \mathrm{XMD}^{2}$

where $H$ is the variable UT hour, $H 0$ is the selected UT hour and XHR is the half-width of the Gaussian weight function for the time-of-day. Correspondingly, $M$ is the variable 
month, $M 0$ is the selected month and XMD is the half-width of the Gaussian weight function for month-of-the year. The summations involved in the averaging are extended to 3 times the width of the Gaussian. The authors are not explicit about the values of XHR and XMD. At present they state, "Typical values in this case are XHR $=3 \mathrm{~h}$ and XMD $=1.5$ month.”. It is unclear what is meant by typical values. Thus, the normalisation coefficients are not reproducable.

Finally all values over the entire interval are averages for each UT hour for each month.

Now that the angle $\phi$ has been found the coefficients $\alpha$ and $\beta$ are then calculated using orthogonal correlation analysis (see Eq. 6 and Table 1). A combination of averaging and smoothing like that described above is used. First the averages of samples for each specific hour and month summed over five consecutive years. Then a 2-D Gaussian smoothing over time-of-day and month-of-year is applied where a weight function with half-width of $2 \mathrm{~h}$ in time and 1 month in season, respectively, is applied and the summation involved in the smoothing process is extended over 3 times the Gaussian width. Tables 4.1, 5.1 and 5.2 in Stauning et al. (2006) give the coefficients. The method is clearly not simple and not independently reproducable.

The values of the coefficients $\alpha$ and $\beta$ and the angle $\phi$ are calculated once only. A table of the hourly coefficients for each month is then used in the definition of the PC index. To obtain the values for times between defined elements a linear relation is assumed.

\subsubsection{The quiet level $(\delta M, \delta N)$}

DMI\#4_2006 calculate the quiet level in two steps. A baseline is determined (basic geomagnetic field intensities (Table 3.1 in Stauning et al., 2006). How this is determined in unclear but at least one year of data are required. Hence the final index cannot be determined until at least one year past. This is subtracted from the measured Horizontal variation (using a linear interpolation from January-January) and then weighted means method is used to determine the daily variation which is static over one month. A linear interpolation is used between months.

The method for obtaining the quiet level is stated in Stauning et al. (2006) but is not clear. The weights used are not explicitly given. However, the quiet day curves account for the seasonal variation in the ionospheric conductivity.

AARI\#3_2006 calculate the quiet level in one step. The method is clearly set out in Janzhura and Troshichev (2008) and will not be reproduced here. The method is reproducable, automatic and a definitive set can be determined. The quiet level is different each day and is dependent on the quiet level in the previous 30 days from the point of calculation. This method is very useful for online calculations.

The results of the Janzhura method are intuitively similar to the Stauning et al. method but the comparison has never been published.

\section{Comparison between the different PC index deriva- tion methods}

Please note: All papers with Troshichev as first author use PCN and PCS calculated using the AARI methods. They are not comparisons between the DMI and the AARI methods (personal communication with Troshichev). The PCN index used by these authors is not the official PCN index from DMI.

\subsection{The normalisation coefficients $\alpha$ and $\beta$, and the angle $\phi$}

Hereafter the term "coefficients" includes the angle $\phi$.

The procedure for the derivation and smoothing of the coefficients is a key point in the index derivation. It should be clearly stated in the published description of the index, so as to make it independently reproducible. Let us recall here that independent reproducibility is a mandatory condition for IAGA endorsement of any index (see Sect. 4). Papitashvili et al. (2001) were unable to locate the coefficients used by Vennerstrom (1991) and, therefore, recomputed these coefficients following Vennerstrom's method and used them for DMI\#2_2001.

AARI \#1_1988 used "15-min average values of the magnetic perturbation in Vostok and Thule, and 5-min averages values of the IMF and the solar wind velocity obtained from the IMP-8 satellite during the IMS period 1977-1980”. They carried out the regression analysis for each UT-hour and each season separately.

AARI \#3_2006 uses 5-min means whereas AARI\#2_1991 and DMI\#4_2006 use 15-min means of satellite and ground data to obtain the one hour regression statistics.

AARI\#3_2006 is extremely unclear about the procedure. In paragraph 8, Troshichev et al. (2006) clearly state the coefficients are determined for each month and UT hour. However they then state in Sect. 2.2 (paragraph 14) that $5 \mathrm{~min}$ parameters over ten day intervals are used and these, not the one hour parameters are subject to the smoothing procedure. Please note that only four years of data are used here. In Troshichev et al. (2007a) it is stated that the calculation of the parameters was extended over 30 years. As a result of the lack of clarity as to the procedure and the data used in determining the coefficients, one is unable to recompute the coefficients using the given description in the currently available published literature.

DMI\#4_2006 procedure is presented above, in Sect. 2.3.1. It has all the necessary elements to reproduce the coefficients within the literature excepting two small questions concerning the derivation. 


\subsubsection{Derivation of coefficients - comparison between years}

The normalisation coefficients are a scaling factor to make the location where the PC index is derived independent within the polar cap (see Papitashvili et al., 2001). Two stations in different locations should exhibit the same PC indices but will have different scaling factors (Papitashvili and Rasmussen, 1999). The idea behind the PC index was to use only ground based data once the normalisation coefficients had been determined (Troshichev et al., 1991). They never considered the change in solar cycle an issue as they thought there existed a direct link between the solar wind electric field and the magnetic field in the polar cap ionosphere.

The first analysis of the coefficients for separate years was by Papitashvili et al. (2001). They calculated the coefficients for each year using three year running means in the solar wind data. They found coefficients were not similar for each year so they concluded the normalisation parameters should be calculated in this way and not left static.

AARI\#3_2006 states (1) that they made a comparison of the coefficients based on data 1998-2001 and only using 2002. They say they achieved similar results but failed to show the result. (2) In the same paper the authors state:

It should be noted that parameters $\alpha, \beta$ and $\phi$, ensuring the best correlation between $\delta F$ and Em, were derived for period of the maximum solar activity. We suppose that these parameters would be invariant during the entire solar cycle, since modification of the ionospheric currents in course of the solar cycle had been taken into account while calculating the quiet daily variation. Nevertheless, we shall verify our supposition by determining the parameters $\alpha, \beta$ and $\phi$ for years of the solar activity decay (2004-2005) and later on for years of the solar activity minimum (2007-2008). If the parameters derived from independent samplings turn out to be closely related, it will mean that relationship between the merging electric field Em and PC index is held invariant irrespective of course of the solar cycle. Otherwise, the each phase of the solar cycle would be provided with proper coefficients $\alpha, \beta$ and $\phi$.

The two statements contradict each other. The authors must be very clear on the invariant nature of the coefficients. The second statement quoted, strongly suggests that the authors feel a change in coefficients from year to year is required and need to test it. This has not been done.

However, DMI\#4_2006 has a well defined analysis for all coefficients derived over 5 year intervals. The data interval is divided into 5 year sequences with a step every two years. The problem is they have overlap in the determination of the coefficients so the suspected changes of the coefficients for these intervals are actually smoothed out in the analysis.

\subsection{Time delay $\Delta T$ from magnetopause $\left(12 R_{E}\right)$ to ground}

DMI\#1_1991 (Vennerstrom, 1991) quotes the Troshichev and Andrezen (1985) paper with a time delay of $T=20 \mathrm{~min}$. AARI\#3_2006 uses $\Delta T=15 \mathrm{~min}$ and say the number comes from Troshichev and Andrezen (1985). However, Troshichev and Andrezen (1985) did not make an analysis of the time delay. Their findings showed a reduced correlation coefficient between the MAGPC index and the emerging electric field, as compared to contemporary works, and surmised this may be due to the fact that they did not take into account a time delay of $\Delta T=15 \mathrm{~min}$ used by their contemporaries.

AARI \#2_1991 analysed the time delay using the definition of the PC index in Eq. (16). They found the optimal time delay for coefficients was $\Delta T=25 \mathrm{~min}$ (see Fig. 1 in Troshichev et al., 1988).

DMI\#4_2006 performed a statistical study (Sect. 7.1, (Stauning et al., 2006)) and found the optimal time delay to be $\Delta T=20 \mathrm{~min}$; Table 4 summarizes their analysis of the time delay. The average difference is denoted S0, the average numerical (robust) difference is denoted $\mathrm{S} 1$ and the average root-mean-square (RMS) difference is denoted S2. For best quality these three parameters should be at minimum and these occur at $\Delta T=20 \mathrm{~min}$. However, the average difference (S0) only varies by 0.001 indicating it is not a selective parameter. Ignoring $\Delta T=10 \mathrm{~min}$ as the differences are large, we find the greatest separation between the average numerical (robust) difference (S1) is 0.08 ; likewise the greatest separation between the average root-mean-square (RMS) differences (S2) is 0.09 . This indicates that values of $\Delta T$ of 15,20 , or 25 are robust to within $9 \%$. Considering the assumptions made in reducing the measuring times to $12 R_{\mathrm{E}}$ this is a very good result.

We conclude, it does not matter if $\Delta T$ is 15,20 , or $25 \mathrm{~min}$; therefore $\Delta T=20 \mathrm{~min}$ could be defined as the optimum time delay using the data set from Stauning et al. (2006).

\subsection{The quiet level $(\delta M, \delta N)$}

As all components are derived from $\delta M, \delta N$, change these and the coefficients completely change. This was shown in Lukianova et al. (2002) and illustrated nicely in Fig. 4 from Lukianova (2007) and also Stauning et al. (2006). This makes a difference to the PC index as illustrated for Vostok by Troshichev et al. (2007b).

Papitashvili et al. (2001) with regards to DMI\#2_2001 and AARI\#2_1991 states: For Qaanaaq, an appropriate daily "quiet level" is deduced from interpolation between the magnetic field's absolute values determined at nighttime hours of quiet winter days in the two consecutive years (Vennerstrom et al., 1994). The "quiet level" for Vostok is determined from quiet days for the examined month (Troshichev et al., 1991).

Thus a major difference between DMI\#2_2001 and the comparative AARI\#2_1991 are the quiet level determination. 
Table 4. Parameters of scatter plots PCN Vs Satellite derived from Stauning et al. (2006) Figs. 7.1 and 7.2.

\begin{tabular}{cllllllll}
\hline & IMP-8 & & \multicolumn{7}{c}{ ACE } \\
\hline$\Delta T$ (min) & 10 & 15 & 20 & 25 & 10 & 15 & 20 & 25 \\
S0 & 0.018 & 0.018 & 0.018 & 0.018 & 0.048 & 0.049 & 0.048 & 0.049 \\
S1 & 0.499 & 0.483 & 0.477 & 0.480 & 0.627 & 0.609 & 0.601 & 0.603 \\
S2 & 0.748 & 0.724 & 0.715 & 0.720 & 0.894 & 0.868 & 0.857 & 0.859 \\
& highest & & lowest & & highest & & lowest & \\
\hline
\end{tabular}

The DMI index takes the quiet night time field only whereas the AARI index has a daily magnetic variation included in it. What is the definition of the index? Is it the amplitude of something from an invariant zero line as determined by DMI\#2_2001? This amplitude will include all solar daily quiet ionospheric variations. Is it a deviation from the solar quiet variation as AARI\#3_2006 and DMI\#4_2006 use? Or should it be something else? Both AARI\#3_2006 and DMI\#4_2006 have chosen to use daily variations to represent the quiet level rather than an absolute level as they assume the emerging electric field $(E m)$ magnetic signature is independent of the "regular" daily variation of the ionosphere.

\subsection{Comparison between PCN and PCS indices}

The only way to show if two methodologies compare is to compare them. A graph showing PCN (AARI\#3_2006) vs. PCN (DMI\#4_2006) would show a true comparison of the methodologies. This was done by Lukianova et al. (2002) for PCS (AARI\#2_1991) and PCN (DMI\#2_2001) whilst the two methods show a linear correlation it is only of medium strength. They also show that when the PCN and the PCS are calculated using the same method the linear correlation is 1.0 for three different data sets (although there is considerable spread): a surprising result which was never acted upon by the two institutes producing the PC indices.

\section{Criteria for endorsement of indices by IAGA}

The following criteria are those submitted to the IAGA secretary General to be included in the Guide for IAGA officers after the IAGA 2009 meeting in Sopron. It may not be the final version.

Separating "properties" of the index from the "process" by which it is endorsed.

Properties: An IAGA-endorsed geomagnetic activity index is one that is derived from magnetic field measurements made at magnetic observatories and that satisfies the following five properties. A proposed index that fails to meet all these criteria shall be deemed to be not endorsed by IAGA but may be proposed for reconsideration at a future IAGA assembly.
1. The index must be shown to describe or quantify a geophysical quantity not already described by existing IAGA indices, or be shown to describe or quantify more effectively and in a statistically meaningful way, a geophysical quantity compared with an existing index.

2. The derivation of the index will be clearly defined; the algorithm will be available through appropriate refereed and citable publication(s); the algorithm must be shown to be independently reproducible and the responsible institute will ensure the homogeneity of the data series over the whole time series.

3. Observatories providing data for the index will be reliable, well-established and fully operational according to current scientific standards. If relocation or change of an observatory happens, the index producer and the relevant IAGA committee will urge for a suitable overlapping operation period of the observatories. In the event that it is not possible the index producer has the responsibility to propose a suitable way for ensuring the data series homogeneity. He should evaluate and document changes to the index and report to the relevant IAGA committee, defined below.

4. Prior to any proposal for endorsement being made, the index must have been freely available for scientific use long enough, so as to be already be in use by the scientific community, as demonstrated by refereed and citable publications.

5. Past, present and future values of the index will be made available via the websites (or appropriate future electronic and published means) of either the host institute or an agreed substitute, and of ISGI once endorsed, to enable independent checks and access to data. The proposers will provide assurances in regard of availability of the index and of the time-lag in producing the index in future and in archiving and access to archived data.

Process: IAGA will consider endorsing a magnetic index according to the following process:

1. Any proposal for endorsement will be made to, and be reviewed by, the IAGA committee that discusses geomagnetic indices, currently working group V-DAT of 
Division V. Any proposal will be made no later than one year prior to an IAGA assembly and will be directed to the chair of the relevant IAGA committee.

2. An ad-hoc "Task Force" of a minimum of three scientific experts will be appointed at the discretion of the relevant IAGA committee chair. The director of ISGI, or an ISGI representative nominated by the ISGI director should be part of the Task Force. The Task group chair will be appointed by the relevant IAGA WG chair; the chairperson should be a scientist with recognized expertise in the field of geomagnetic indices. The Task Force will assess the proposed index, its qualities, and its compliance with the five index criteria. (see "properties"). The Task Force will be provided with relevant supporting material (electronic and printed) by the proposers, not less than six months before the IAGA meeting where endorsement is sought.

3. The Task Force will provide a majority report to the relevant IAGA committee during the IAGA assembly where endorsement is sought. Where the report findings are not unanimous, the minority report(s) shall also be presented at the relevant IAGA committee meeting.

4. The proposed geomagnetic index will be endorsed at a business meeting of the relevant IAGA committee through a majority member vote, and through a subsequent resolution supported by the IAGA Executive Committee.

5. A successful application will be advertised by the IAGA committee chair through relevant scientific publications, such as the IAGA News. If unsuccessful, the proposers will be provided with the points of failure by the Task Force chair, and be invited to resubmit their application at a subsequent IAGA assembly. After three failed attempts, the proposed index shall no longer be considered by IAGA.

\section{The IAGA meeting discourses}

Have the current PC indices been endorsed at an IAGA meeting? The answer is no.

The last geomagnetic index to be formally endorsed by IAGA was the aa index in 1975 (IAGA Bulletin 37, 195, p. 128, resolution 3): over thirty years ago. In all cases where an IAGA index was adopted a rigorous checking procedure was involved, mainly through peer reviewed journals. The initial request presented at the IAGA Madrid meeting in 1969 was to extend the $\mathrm{Ci}$ index backward. However, there were not enough observatories to accomplish this. The aa index was formulated and 7 years later accepted as the official long term planetary index.

A similar story surrounds the formulation of the PC index. At the 8th Scientific IAGA assembly in Uppsala 1997 it was suggested that the PC index may be useful for monitoring the polar cap region and proposed the continuation of its derivation:

IAGA, noting the effectiveness of the Polar Cap (PC) geomagnetic activity index for prompt characterisation of the magnetosphere, and recognising the great contribution of the Arctic and Antarctic Research Institute (AARI) and Danish Meteorological Institute (DMI) in producing and testing the preliminary PC index time series since 1977, emphasises that the usefulness of such an index is dependent on having a continuous data series and urges that all possible effort be made to maintain continuous operation of the stations contributing to this index, and to provide the PCindex to the international scientific community in near-real time via satellite data links. (Resolution No. 4: PC Index (Divisions III and V), IAGA News No. 37, Page 17-22, 1997: cited from electronic document IAGA_Resolutions_v9.pdf, Revision date: 17 August 2005, Page 12-13)

At the IUGG meeting in Birmingham, England 1999 the working group which discusses magnetic indices discussed the PC index:

During the IAGA 1997 (Uppsala), Working Group V2 formed a task force to prepare a report on the Polar Cap Magnetic Activity (PC) Index for circulation within the community. The task force did not complete the report in time for IAGA, Birmingham, however the World Data Centre for Geomagnetism, Copenhagen has a brief report on the PC Index available at URL (http://web.dmi.dk/ fsweb/Projects/wdcc1/pcn/pci-iaga.pdf). Because the PC Index is widely used and referenced in literature, many feel the Working Group should recognize it as an IAGA index. Concern about the longterm ability to derive the index was expressed. Therefore, Dr. Troshichev, with Dr. Rassmussen (sic) and Dr. Papitashvilli (sic) will produce report describing the PC family, method of producing, and use of index in sufficient detail to enable others to continue to produce the index. The report should include such things as a table of coefficients. Richard Coles and Michelle Minvielle (sic) will referee the report. Upon completion of this process, the WGV2 (chairs) will draft a letter for the President of IAGA to send to the institutes operating Thule (Greenland) and Vostok (Antarctica) stations. The letter will inform the institutes of the value of the PC index, IAGA's intention to adopt the PC Index as an official IAGA index, acknowledge their past support and look forward to continuing support for these key stations. Dr. Barton offered to review letter (Minutes of IAGA Division 
International Association for Geomagnetism and Aeronomy

DIVISION V: GEOMAGNETIC OBSERVATORIES, SURVEYS AND ANALYSES

\section{Polar Cap (PC) Magnetic Activity Index}

O. A. Troshichev ${ }^{1}$, O. Rasmussen ${ }^{2}$, and V. O. Papitashvili ${ }^{2,3}$

${ }^{1}$ Department of Geophysics, Arctic and Antarctic Research Institute, St. Petersburg, Russia
${ }^{2}$ Solar-Terrestrial Physics Division, Danish Meteorological Institute, Copenhagen, Denmark
${ }^{3}$ Space Physics Research Laboratory, University of Michigan, Ann Arbor, Michigan, U.S.A.

The PC-index has been introduced by Troshichev et al. [1979, 1988] as an index for monitoring geomagnetic activity over the polar caps caused by changes in the interplanetary magnetic field (IMF) and solar wind. Troshichev and Andrezen [1985] have shown that ground geomagnetic disturbances measured at a single near-pole station highly correlate $(r>0.8)$ with the "merging electric field" $\mathrm{E}_{\mathrm{m}}$ applied to the Earth's magnetosphere [Kan and Lee, 1979]:

$$
\mathrm{E}_{\mathrm{m}}=\mathrm{V}_{\mathrm{SW}} \mathrm{B}_{\mathrm{T}} \sin ^{2}(\theta / 2)=\mathrm{V}_{\mathrm{SW}}\left(\mathrm{B}_{\mathrm{y}}{ }^{2}+\mathrm{B}_{\mathrm{z}}{ }^{2}\right)^{1 / 2} \sin ^{2}(\theta / 2)
$$

Here $V_{S W}$ is the solar wind velocity, $B_{y}$ and $B_{z}$ are the IMF azimuthal and vertical components, respectively, and $\theta$ is the IMF "clock-angle" measured between the Earth's magnetic field vector and $\mathrm{B}_{\mathrm{T}}$.

The algorithm to derive the PC-index is based on a statistical analysis of the relationship between variations in $\mathrm{E}_{\mathrm{m}}$ and geomagnetic perturbations $\Delta \mathrm{F}$ at the Earth's surface. Two near-pole magnetic observatories were proposed for derivation of the index: Qaanaaq (Thule) in Greenland at $85.4^{\circ}$ corrected geomagnetic (CGM) latitude and Vostok in Antarctica at $-83.4^{\circ}$. Since a near-pole station is located under the sunward, transpolar portion of the two-cell ionospheric current system DP2, observed magnetic perturbations point approximately towards dusk. The exact direction is slightly varying in time because DP2 is somewhat skewed with respect to the noonmidnight meridian. Thus, the transverse magnetic perturbation caused by the DP2 transpolar current can be written as:

$$
\Delta \mathrm{F}_{\mathrm{PC}}=\Delta \mathrm{H} \sin \gamma \pm \Delta \mathrm{D} \cos \gamma
$$

where $\gamma=\lambda \pm \mathrm{D}_{\mathrm{E}}+\varphi+\mathrm{UT} \cdot 15^{\circ}$. Here $\Delta \mathrm{H}$ and $\Delta \mathrm{D}$ are deviations in the ground horizontal $H$ and $D$ magnetic field components from the pre-selected quiet level, $\mathrm{D}_{\mathrm{E}}$ is the station's average declination angle, $\lambda$ is its geographical longitude, and $\varphi$ is the UT-dependent angle between the DP2 transpolar current and the noon-midnight meridian. "+" is used for Vostok, and "-" for Qaanaaq. The quiet level is deduced for Qaanaaq by interpolating between field's values determined at nighttime hours of quiet winter days in the two consecutive years. The quiet level for Vostok is determined from quiet days for the examined month.

The "true" angle $\varphi$ is obtained through a correlation analysis relating $\mathrm{E}_{\mathrm{m}}$ and horizontal magnetic perturbations projected on various directions; the direction where correlation is maximal is then used for derivation of the index. Figure 1 shows optimal directions obtained at Vostok and Qaanaaq (Thule)

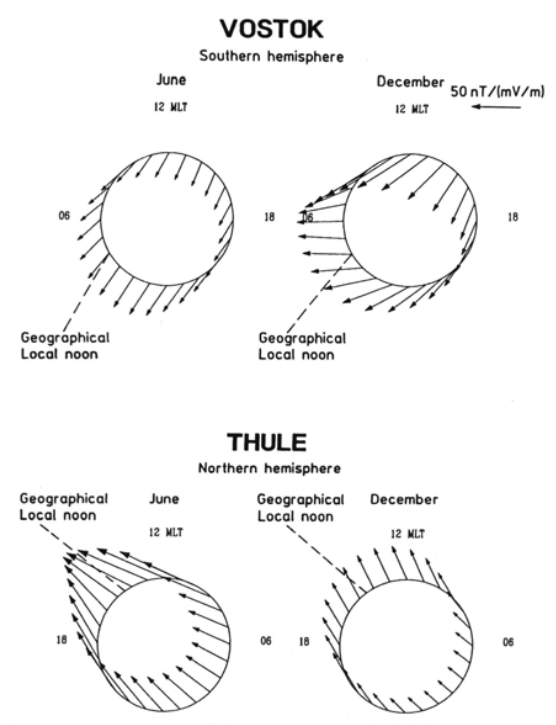

Figure 1. The CGM latitude - MLT diagram for the selection of optimal directions in the PC index derivation [after Vennerstrom et al., 1994].

Fig. 6. The paper presented to IAGA that was later removed from circulation. Please note the PC index is still under review and thus has not been endorsed by IAGA.

\section{V-dat WG meeting, Polar Cap Magnetic Activity (PC) Index 1999).}

It is clear from the minutes of this meeting that the PC index is supported by the working group.

The report prepared by Papitashvili that is referred to in the working group minutes was modified after the working group meeting. The report presented to the working group is reproduced in Fig. 6 with the endorsement note from the executive committee (Papitashvili and Menvielle) added in 2001. The document should have the full methodology of calculating the index. It clearly does not.
The endorsement was revoked in 2001. Since the document existed in public view for even a brief period a letter revoking the document should have been written, rather than just removing it from public view so there would have been a clear understanding of the position of the index within the IAGA community. Nevertheless it was known by the IAGA community that this document was revoked.

The document with the endorsement is referenced in Stauning et al. (2006) page 2, and again by Stauning et al. (2008) page 2247: 
for June and December. It was found that these optimal directions vary with UT and season; therefore, the projected horizontal perturbation $\Delta \mathrm{F}_{\mathrm{PC}}$ should be normalized with respect to $\mathrm{E}_{\mathrm{m}}$ :

$$
\Delta \mathrm{F}_{\mathrm{PC}}=\alpha \cdot \mathrm{E}_{\mathrm{m}}+\beta \text { and } \mathrm{PC}=\left(\Delta \mathrm{F}_{\mathrm{PC}}-\beta\right) / \alpha \cdot \eta
$$

where $\alpha$ (slope) and $\beta$ (intercept) are functions of local time and month, and $\eta=1 \mathrm{mV} / \mathrm{m}$ is a normalization coefficient required to make the PC index dimensionless. The PC index is now calculated from a set of 12 (months) by 24 (hourly) values of the coefficients $\alpha$ and $\beta$ and angles $\varphi$. These coefficients have independently been determined for Qaanaaq and Vostok for the period when good coverage of the IMF data has been available. For example, Figure 2 shows contour plots of the coefficients $\alpha$ and $\beta$ obtained for Thule as functions of the months and UT hour. Further investigation of the PC-index is underway [e.g., Papitashvili and Rasmussen, 1999; Troshichev et al., 2000]

The World Data Center B2 (Moscow, Russia) and the NOAA National Geophysical Data (Boulder, Colorado, U.S.A.) have published the index catalogs [e.g., Troshichev et al., 1991; Vennerstrom et al., 1994]; NGDC has also made PC-index available through regular publications. Currently the Northern PC index is continuously derived from geomagnetic data obtained at Qaanaaq; the Southern PC index - from geomagnetic data obtained at Vostok. Both indices are available on-line from the Danish Meteorological Institute (Copenhagen, Denmark, http://www.dmi.dk/projects/wdcc1/pcn) and from the Arctic and Antarctic Research Institute (St. Petersburg, Russia, http://www.aari.nw.ru).

The International Association of Geomagnetism and Aeronomy (IAGA) has officially adopted the Polar Cap (PC) Magnetic Activity Index at the $22^{\text {nd }}$ General Assembly of International Union of Geodesy and Geophysics (IUGG, Birmingham, UK, July 1999). It has been recommended by IAGA that the service should be continued for both the Northern and Southern polar caps in near future upon availability of resources at DMI and AARI.

\section{References}

Kan, J. R., and L. C. Lee, Energy coupling function and solar wind-magnetosphere dynamo, Geophys. Res. Lett., 6, $577,1979$.

Papitashvili, V. O., and O. Rasmussen, Effective area for the northern polar cap magnetic activity index, Geophys. Res. Lett., 26, 2917, 1999.

Troshichev, O. A., and V. G. Andrezen, The relationship between interplanetary quantities and magnetic activity in the southern polar cap, Planet. Space Sci., 33, 415, 1985.

Troshichev, O. A., N. P. Dmitrieva, and B. M. Kuznetsov, Polar cap magnetic activity as a signature of substorm development, Planet. Space Sci., 27, 217, 1979.

Troshichev, O. A., V. G. Andrezen, S. Vennerstrøm, and E. Friis-Christensen, Magnetic activity in the polar cap - A new index, Planet. Space Sci., 36, 1095, 1988.

Troshichev, O. A., V. G. Andrezen, S. Vennerstrøm, and E. Friis-Christensen, Polar Cap (PC) Geomagnetic Activity Index for 1975-1982, WDC-B2, Soviet Geophysical Committee, Academy of Sciences of the USSR, Moscow, 142 pp., 1991.

Troshichev, O. A., R. Yu. Lukianova, V. O. Papitashvili, F. J. Rich, and O. Rasmussen, Polar cap index (PC) as a proxy for ionospheric electric field in the near-pole region, Geophys. Res. Lett., 27, in press, 2000.

Vennerstrøm, S., E. Friis-Christensen, O. A. Troshichev, and V. G. Andrezen, Geomagnetic Polar Cap (PC) Index 1975-1993, Report UAG-103, WDC-A for Solar-Terrestrial Physics, NOAA/NGDC, Boulder, Colorado, 274 pp., 1994.

Fig. 6. Continued.

The development of a PC index was recommended by IAGA in 1999 and the index was later adopted by IAGA as an international standard index on the condition that a unified procedure for the PC index calculations was defined. This unification has now been accomplished through cooperation between the Arctic and Antarctic Research Institute (AARI) responsible for the PCS index, and the Danish Meteorological Institute (DMI) responsible for the PCN index (see Troshichev et al., 2006).
The document with the endorsement note should not have been referenced again regardless of its previous brief existence. It is clear from the texts above reproduced that IAGA recommend the development of the index in 1997 not 1999; Furthermore the document referenced by Stauning et al. (2008) as Troshichev et al. (2001) is the report reproduced in Fig. 6. It was actually written in 1999 but again they are referring to that document that was modified in 2001 and revoked in 2001. Unfortunately, the index has not been endorsed by IAGA as the unified procedure is still a contentious issue. 
Papitashvili et al. (2001) found the PCN index contained an error. They rectified the error and recalculated the index (not the coefficients).

The Sapporo 2003 V-dat minutes state that "ISGI reports reconsideration of $P C$ index and rapid variations." No reasons are stated within the minutes. We can only surmise that an extensive discourse took place. Therefore even if no IAGA resolution was written at this stage it is clear that the Vdat commitee no longer accepted the index as a candidate for IAGA endorsement in the form it was presented. Please note that the ISGI representative was M. Menvielle an expert in geomagnetic indices. The full explanation of the derivation of the index was not available in the literature at this time and it had been noted that the index contained a seasonal daily variation which had not been addressed (Papitashvili et al., 2001). The scientific community are very interested in the index as during this time several papers were written using and testing the index as it has been evolving.

At the meeting in Toulouse 2005 the PC index was again discussed by the V-dat members:

PC may yet be endorsed provided the derivation process is clearly stated and does not change. The current position with regard to the data generation and continuity is to be clarified with AARI (Oleg Troschichev (sic)). A PC paper has been prepared and can be circulated to and discussed with WG chair and co-chair (see Actions). H Macreadie (sic) stated that the PC index was not endorsed by IAGA but it is available on the website. However, V Papitashvilli (sic) said that it was originally endorsed but that the endorsement was later withdrawn, pending clarification. (PC Index and current status (M Menvielle): Minutes of meeting 2005; IAGA Division V-dat).

Please note that Papitashvili was referring to the revoked document. Hence the statement that the index was once endorsed. No paper was circulated.

The IAGA meeting in Perugia (2007) states:

PCN and PCS have been recomputed to bring out a unifying PC index which is available in near real time at the DMI website. Papitashvili added that in general, any new index should be reviewed before they are accepted. (PC Index and current status (Stauning); Minutes of meeting 2007; IAGA Division V-dat)

However, the derivation process was not made clear enough in the for the V-dat members; the index was still not endorsed.

Finally in Sopron (2009)

Dr. McCreadie prepared a comprehensive report after going through several related documents and with contributions from Drs. Stauning and
Troshichev. The report included a brief history of IAGA's involvement with PC. The index is definitely useful. The definition of the Staunings PCN index and AARI PCS index is unified and it definitely has an affinity with the PC merging electric field. It was noted that the way the indices are computed is different. The current index is not yet at its final stage of development. The official PCN index is no longer compatible with the PCS index. The WG recommends that a comprehensive report with details of all issues regarding the derivation of the coefficients and calculation of actual PC index values be written within one year. The report should be reviewed by the Task Force and be published e.g. at ISGI website in order to provide a basis for a final decision on endorsement by IAGA at the 2011 meeting. (Status of PC as an IAGA Index (McCreadie); Minutes of meeting 2009; IAGA Division V-dat)

\section{Conclusions}

This document attempted to examine the derivation of the PC indices using the current literature so that the index derivation could be understood by a novice and computed independently. It could not be done for any of the indices. Thus, item 2 of the "Criteria for endorsement of indices by IAGA" (see Sect. 4) failed.

We have shown here that the derivation of the PC index is unique for each of the three main sources (AARI\#3_2006, DMI\#2_2001 and DMI\#4_2006) even though AARI\#3_2006 and DMI\#4_2006 claim to be unified. Thus, the PC index is not unified.

The official PCN index available at DMI (DMI\#2_2001) can never be reproduced as the method for deriving the constants used cannot be repeated. If the constants do not require recalculation then this index could be determined ad infinitum. However, the quiet level determination lacks the daily ionospheric conductivity levels. Thus, the official PCN index and the official PCS index are no longer compatible.

There is still confusion surrounding the solar cycle variation of the coefficients using the new quiet level methodology. Troshichev et al. (2006) suggests that the coefficients may change, thus altering the index determination. Thus, the final version of the PC index has still not been written.

The current PC index (PCN and PCS) are still "research" indices and cannot be accepted by IAGA until the main authors of the current PC indices agree on ONE final unified index derivation procedure and submit a paper describing its full methodology written in a way that a novice can reproduce the index, as soon as they can. A full worked example with emphasis on the derivation of the PC index coefficients would be helpful. 
Acknowledgements. For the 2009 IAGA meeting in Sopron, Hungary we were asked to write a review of the methodology of the PC index. A first draft of this document was presented to the Vdat community. It was well received and we were urged to publish the contents in a peer reviewed journal. The authors thank their colleagues for continuing support and discussion. Much of this text is based on personal communication between Peter Stauning and Oleg Troshichev as well as the PC index committee (Michel Menvielle, Heather McCreadie, Renata Lukianova), Chair of working IAGA group V-dat, Mita Rajaram, and Co-chair division V, Alan W. P. Thomson.

Topical Editor K. Kauristie thanks V. P. Papitashvili and another anonymous referee for their help in evaluating this paper.

\section{References}

Aitken, A. C.: Statistical Mathematics, edited by: Oliver, T. and Boyd, G., Edinburgh and London (fifth edition, first edition 1939), 1947.

Hald, A.: Statistiske metoder, Akademisk Forlag, Kobenhavn, cited from Vennerstrom (1991), 1968.

Janzhura, A. S. and Troshichev, O. A.: Determination of the running quiet daily geomagnetic variation, J. Atmos. Solar-Terr. Phys., 70, 962-972, doi:10.1016/j.jastp.2007.11.004, 2008.

Kan, J. R. and Lee, L. C.: Energy coupling function and solar wind-magnetosphere dynamo, Geophys. Res. Lett., 6(7), 577580, 1979.

Kuznetsov, B. M. and Troshichev, O. A.: On the nature of polar cap magnetic activity during undisturbed periods, Planet. Space Sci., 25, 15-21, 1977.

Lukianova, R., Troshichev, O., and Lu, G.: The polar cap magnetic activity indices in the southern (PCS) and northern (PCN) polar caps: consistency and discrepancy, Geophys. Res. Lett., 29(18), 1879, doi:10.1029/2002GL015179, 2002.

Lukianova, R.: Comment on Unified PCN and PCS indices: method of calculation, physical sense, dependence on the IMF azimuthal and northward components by O. Troshichev, A. Janzhura, and P. Stauning, J. Geophys. Res., 112, A07204, doi:10.1029/2006JA011950, 2007.

Mayaud, P. N.: Derivation, meaning and use of geomagnetic indices, Geophysical Monograph, 22, 1980.

Papitashvili, V. O. and Rasmussen, O.: Effective area for the northern polar cap magnetic activity index, Geophys. Res. Lett., 26(19), 2917-2920, 1999.

Papitashvili, V. O., Gromova, L. I., Popov, V. A., and Rasmussen, O.: Northern Polar Cap magnetic activity index PCN: Effective area, universal time and solar cycle variations, Scientific Report 01-01, Danish Meteorological Institute, Copenhagen, Denmark, pp. 57, 2001.
Stauning, P., Troshichev, O. A., and Janzhura, A. S.: Polar Cap (PC) index. Unified PC-N (North) index procedures and quality. Scientific Report 06-04, Danish Meteorological Institute, Copenhagen, Denmark, 2006.

Troshichev, O. A., Dmitrieva, N. P., and Kuznetsov, B. M.: Polar cap magnetic activity as a signature of substorm development, Planet. Space Sci., 27, 217-221, 1979.

Troshichev, O. A.: Polar magnetic disturbances and field-aligned currents, Space Sci. Rev., 32, 275-360, 1982.

Troshichev, O. A. and Andrezen, V. G.: The relationship between interplanetary quantities and magnetic activity in the southern polar cap, Planet. Space Sci., 33, 415-419, 1985.

Troshichev, O. A., Andrezen, V. G., Vennerstrom, S., and FriisChristensen, E.: Magnetic activity in the polar cap - A new index, Planet. Space Sci., 36, 1095-1102, 1988.

Troshichev, O. A., Andrezen, V. G., Vennerstrom, S., and FriisChristensen, E.: Polar Cap index (PC) geomagnetic activity index for 1975-1982, WDC-B2, Soviet Geophysical Committee, Academy of Sciences of the USSR, Moscow, 1-142, 1991.

Troshichev, O. A., Janzhura, A. S., and Stauning, P.: Unified PCN and PCS indices: method of calculation, physical sense and dependence on the IMF azimuthal and northward components, J. Geophys. Res., 111, A05208, doi:10.1029/2005JA011402, 2006.

Troshichev, O. A., Janzhura, A., and Stauning, P.: Magnetic activity in the polar caps: Relation to sudden changes in the solar wind dynamic pressure, J. Geophys. Res., 112, A11202, doi:10.1029/2007JA012369, 2007a.

Troshichev, O. A., Janzhura, A. S., and Stauning, P.: Reply to Comment of R. Lukianova, R. on paper "The unified PCN and PCS indices: method of calculation, physical sense, dependence on the IMF azimuthal and northward components" by O. Troshichev, A. Janzhura, and P. Stauning, J. Geophys. Res., 112, A07205, doi:10.1029/2006JA012029, 2007b.

Troshichev, O. A., Janzhura, A. S., and Stauning, P.: Correction to "Unified PCN and PCS indices: Method of calculation, physical sense, and dependence on the IMF azimuthal and northward components", J. Geophys. Res., 114, A11202, doi:10.1029/2009JA014937, 2009.

Vennerstrom, S.: The geomagnetic activity index PC, PhD Thesis, Scientific Report 91-3, Danish Meteorological Institute, 105 pp., 1991.

Vennerstrom, S., Friis-Christensen, E., Troshichev, O. A., Andrezen, V. G.: Comparison between the polar cap index PC and the auroral electrojet indices AE, AL and AU, J. Geophys. Res., 96, 101-113, 1991.

Vennerstrom, S., Friis-Christensen, E., Troshichev, O. A., and Andrezen, V. G.: Geomagnetic Polar Cap (PC) Index 1975-1993, Report UAG-103, WDC-A for STP, NGDC, Boulder, cited from Papitashvili et al., 2001, 1994. 